\title{
Effects of spouses' involvement in pregnancy on fear of childbirth in nulliparous women
}

\author{
F. Jamali ${ }^{1}$, F. Olfati ${ }^{2}$, S. Oveisi ${ }^{3}, \underline{\text { F. Ranjkesh }}^{2}$
}

\author{
${ }^{1}$ School of Nursing and Midwifery, Qazvin University of Medical Sciences, Qazvin, Iran \\ ${ }^{2}$ School of Nursing and Midwifery, Midwifery Faculty, Qazvin University of Medical Sciences, Qazvin, Iran \\ ${ }^{3}$ Metabolic Diseases Research Center, School of Medicine, Qazvin University of Medical Sciences, Qazvin, Iran \\ Corresponding Address: Fatemeh Ranjkesh, School of Nursing and Midwifery, Qazvin University of Medical Sciences, \\ Bahonar Blvd., Qazvin, Iran \\ Tel: +98-912-1825021, Email: franjkesh@qums.ac.ir \\ Received: 14 Oct 2017; Accepted: 18 Dec 2017
}

\section{Abstract}

Background: Maternal request for caesarean section due to fear of normal vaginal delivery is one of the main reasons for the high rate of caesarean section.

Objective: The aim of this study was to examine the effect of the presence of spouse in preparation class of delivery on fear of parturition in the nulliparous women.

Methods: This controlled randomized trial was conducted in 152 pregnant women nulliparous referred to delivery preparation class in Qazvin. We received informed consent from participants. The samples were randomly assigned to intervention $(n=76)$ and control groups $(n=76)$. Eight sessions of the childbirth preparation classes were held for the intervention and control groups with or without the spouse respectively. Data collection tools were demographic characteristics and childbirth attitude questionnaire. Statistical testes such as T-test, and repeated measure were used for analysis.

Findings: The mean age of the mothers participating in the study was $25.85 \pm 4.42$ years. The decrease in mean of fear scores in the intervention group was significantly higher than the control group (28.58 \pm 6.47 and 32.82 \pm 5.79 , respectively) $(\mathrm{P}<0.001)$. A significant difference was also observed between two groups in the rate of selection of normal vaginal delivery $(\mathrm{P}<0.001)$.

Conclusion: The results of the study showed that the presence of a spouse in preparation class of delivery reduces the amount of childbirth fear and is suggested as one of the methods of implementing pregnant women's education program.

Keywords: Nulliparous women, Childbirth, Pregnancy, Men's participation

Citation: Jamali F, Olfati F, Oveisi S, Ranjkesh F. Effects of spouses' involvement in pregnancy on fear of childbirth in nulliparous women. J Qazvin Univ Med Sci 2018; 22(2): 38-47. 


\title{
تأثير مشاركت همسر در كلاس آمادكى براى زايمان بر ترس از زايمان زنان نخستزا
}

\author{
فاطمه جمالى '، دكتر فروزان الفتى"، دكتر سونيا اويسى"، فاطمه رنجكش؟
}

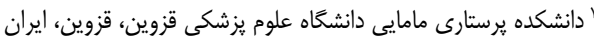

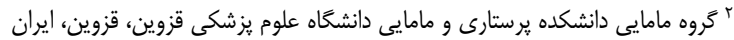

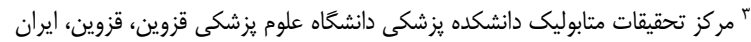

زمينه: ترس از زايمان يكى از شايعترين علل انتخاب زايمان سزارين در زنان نخستزا مى إنىاشد. سازمان بهداشت جهانى بر ترويج مشاركت مـردان

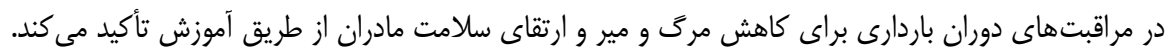

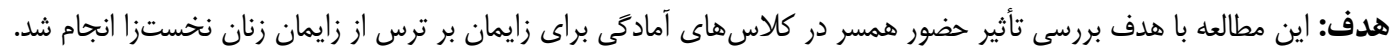

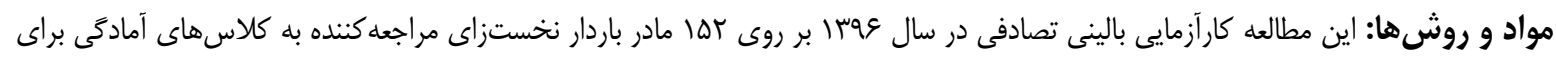

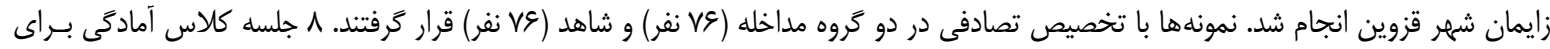

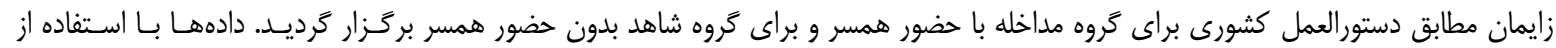

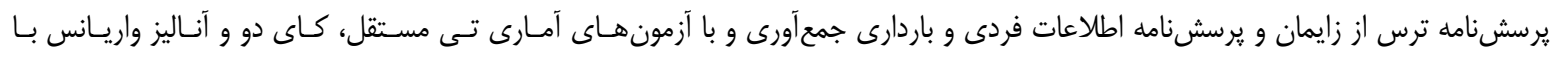

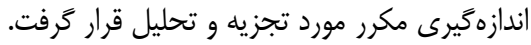

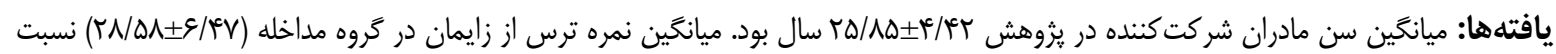

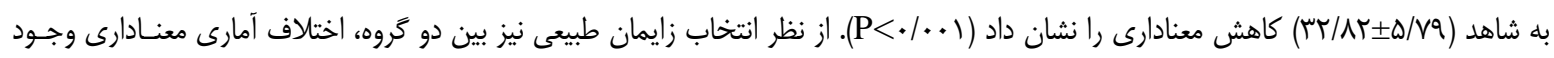

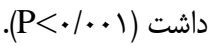

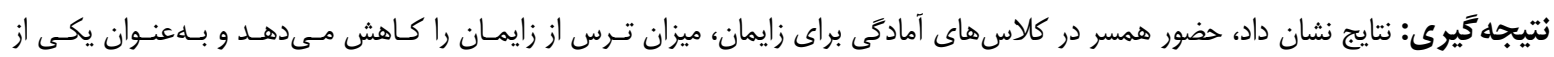

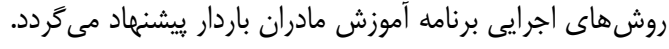

كليدوازهها: زنان نخستزا، باردارى، زايمان، مشاركت همسران

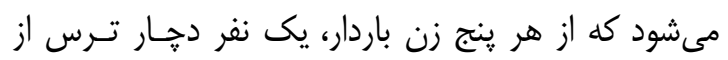

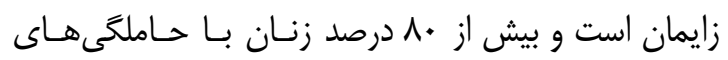

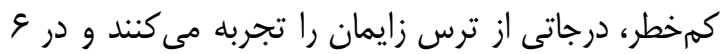

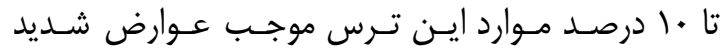

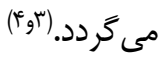

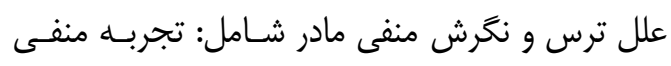

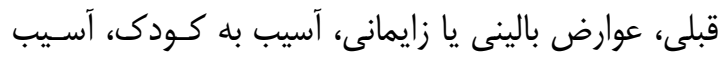

ترس از زايمان، ديدكاهى منفى است كه از دوره قبـل

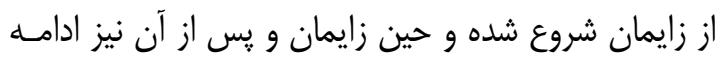

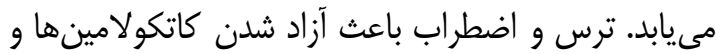

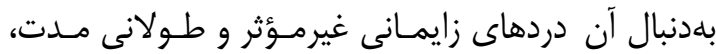

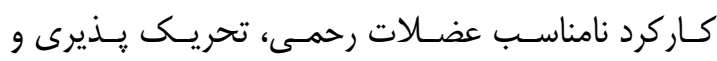

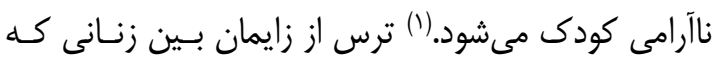

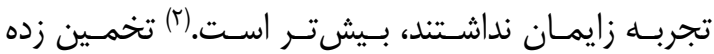




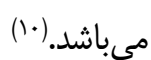
با توجه به فوايد مشاركت مـردان، تـاكنون مشـاركت

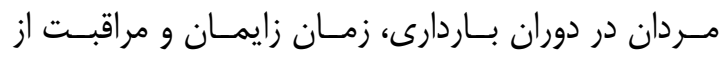

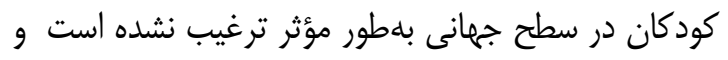

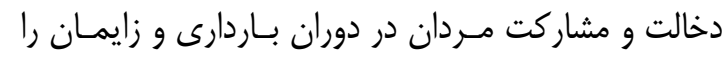

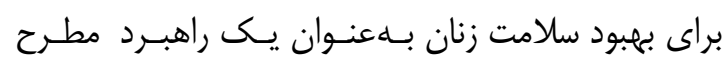

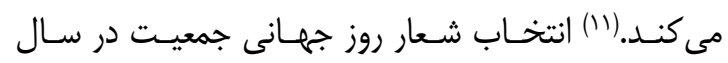

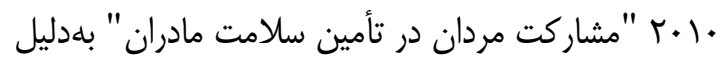

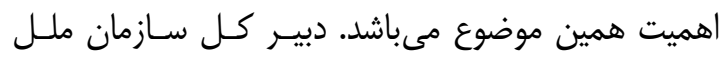

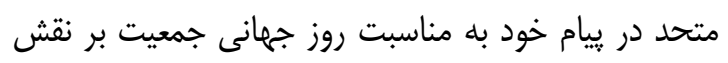

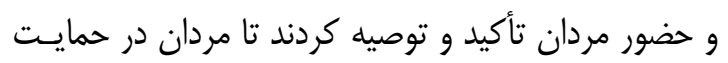

و شركت در برنامههاى مادرى ايمن تشويق شوند.|(I)

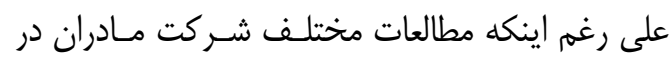

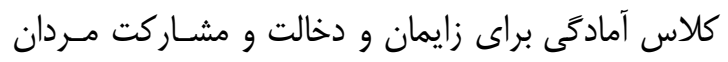

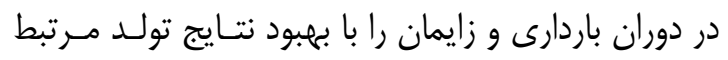

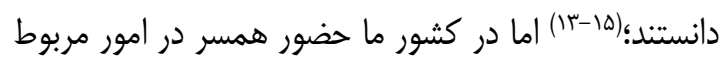

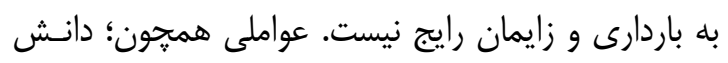

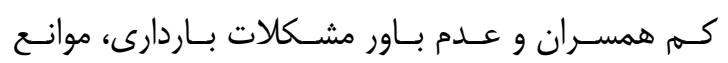

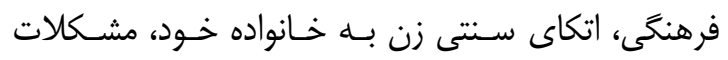

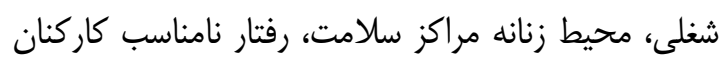
بهداشتى درمانى، عوامل عرفى و مشكلات مالى از جملـه مانه

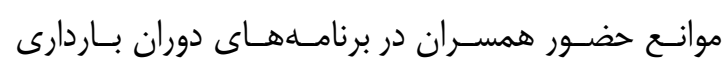
مىباشد. موانع جصور در راستاى بهبود و تغيير برنامههاى بهداشتى مـادران

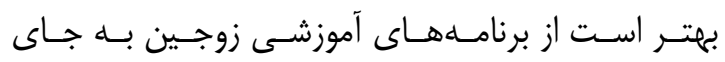

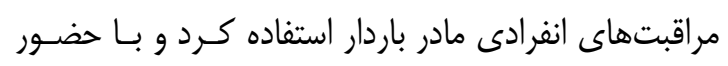

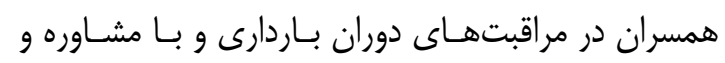

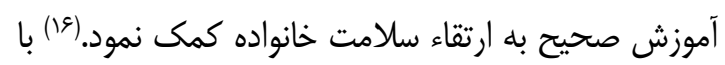
توجه بله سياستهاى جديد جمعيتى و فرزنسدآورى، طـرح

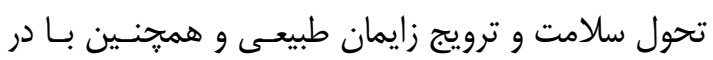

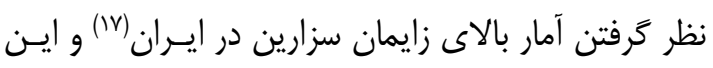

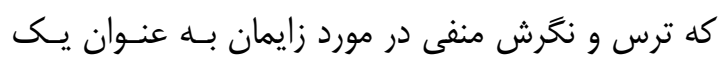

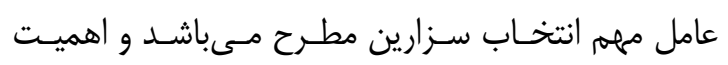

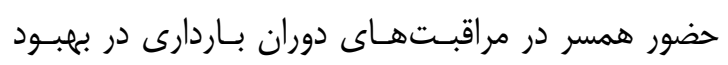

به مادر، بـىاعتمـادى بــه كاركنـان بيمارسـتان مسىباشـــ.

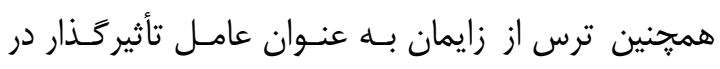

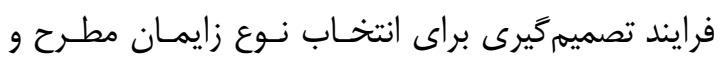

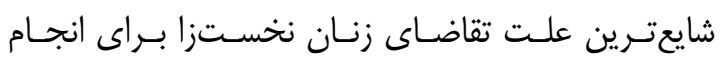
سزارين مىباشد. (1)

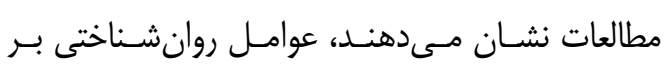

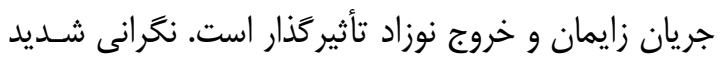

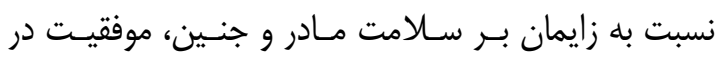

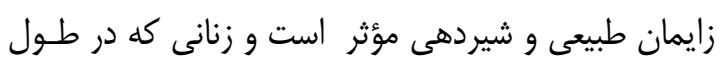

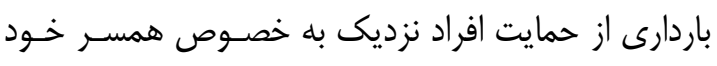

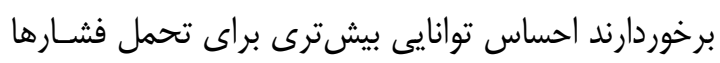

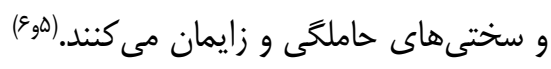

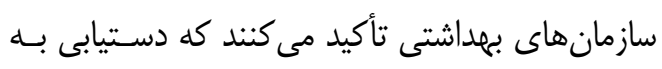

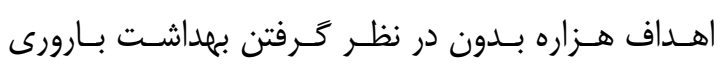

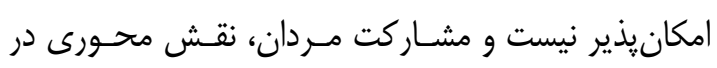

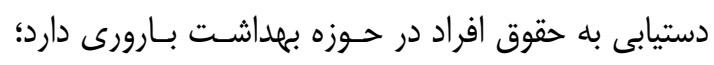

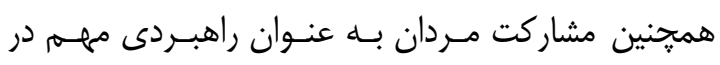

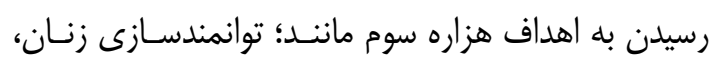

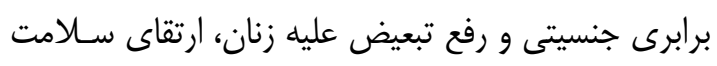

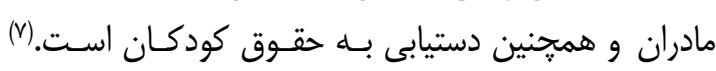

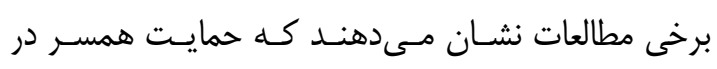

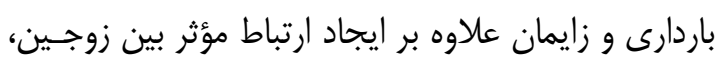

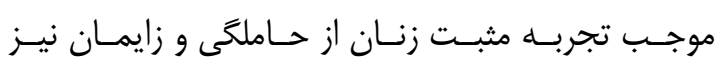

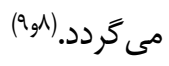

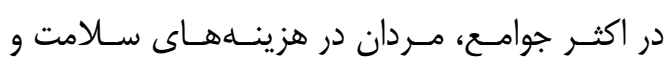

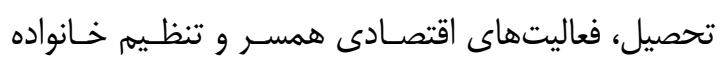

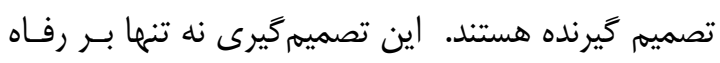

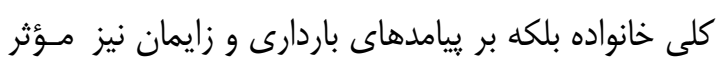

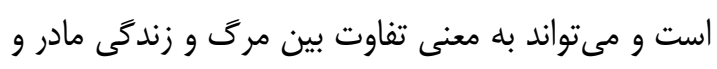

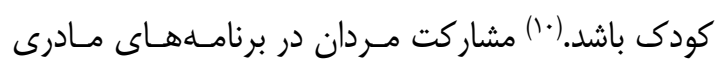

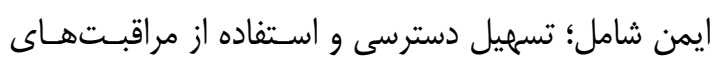

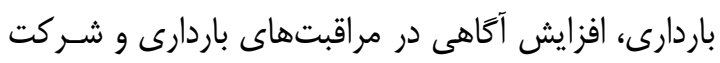

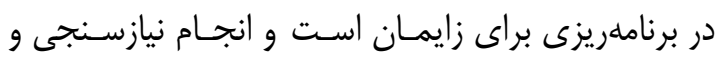

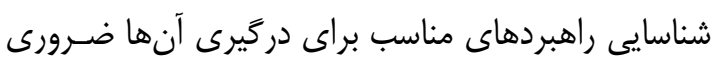


بخواهند مىتوانند از مطالعه خارج شوند.

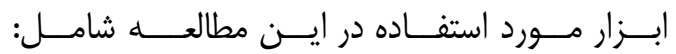

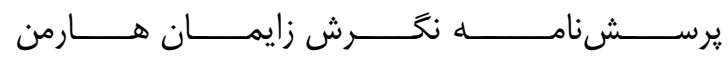
(Childbirth attitudes questionnaire Harman, CAQ)

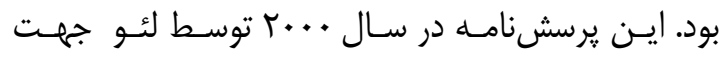

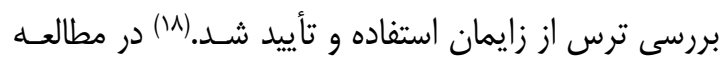
خورسـندى و همكاران تحت عنوان "تــأثير تن آرامى بر زير

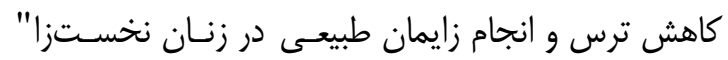

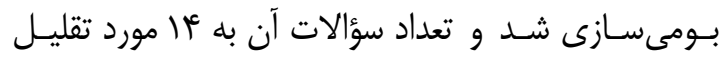

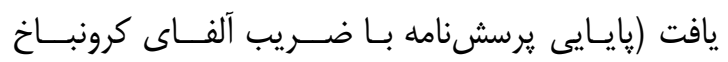

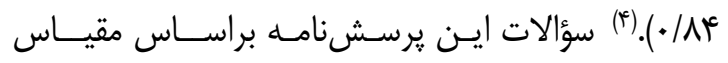

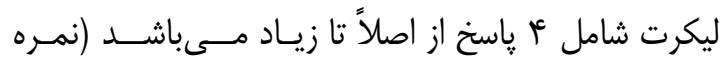

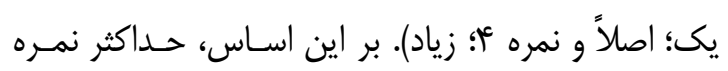

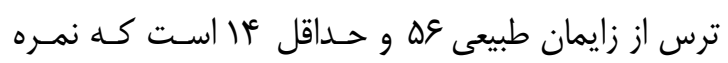

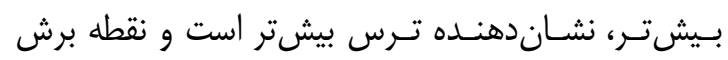
آن مب مي باشد. يرسشنامه اطلاعـات فـردى و بـاردارى شـامل سـهـ بخش اطلاعات جمعيت شناختى (سن، ميزان تحصـيلات

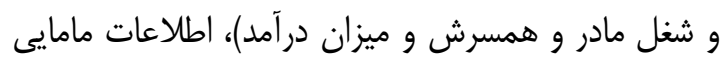

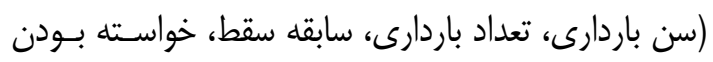

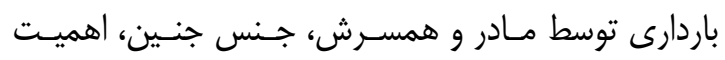

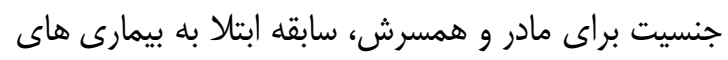

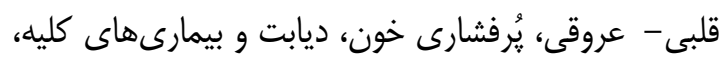

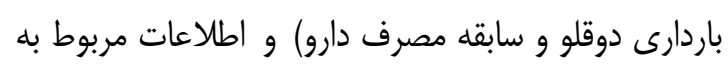

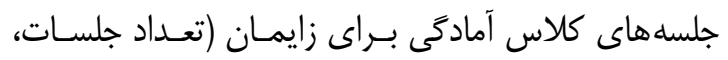

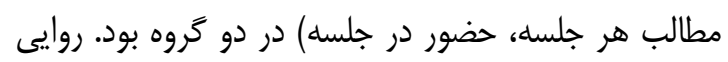

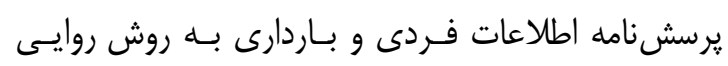

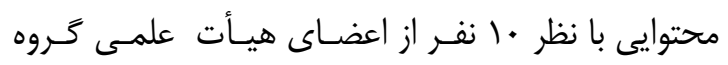

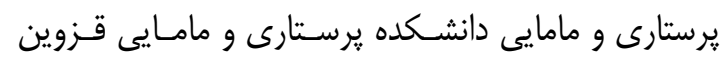
تعيين شد.

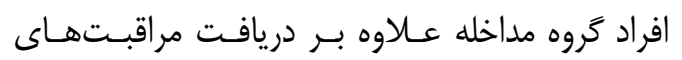
معمول دوران باردارى بلهمدت ^ جلسه در كلاس آمـادگى ماخى

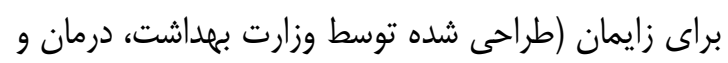

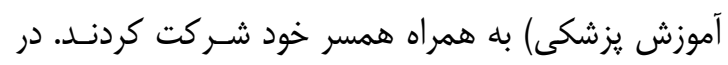

سلامت زنان، مطالعه حاضر با هدف بررسى تـأثير حضـور

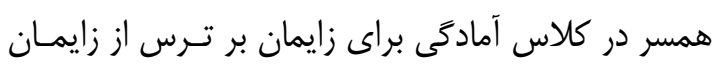
زنان نخستزا طراحى كرديد.

\section{مواد و ورشها:}

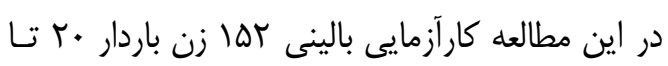

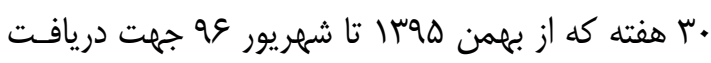

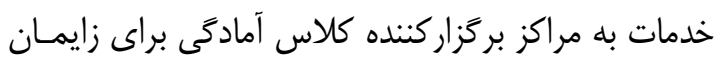

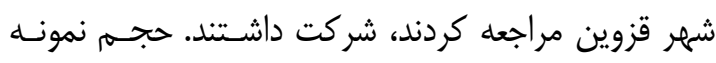

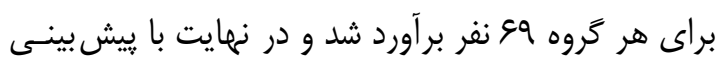

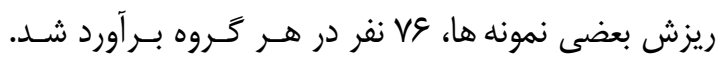

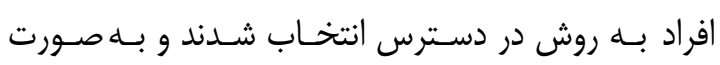

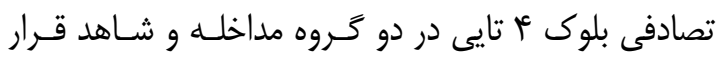
كرفتند. معيارهاى ورود به مطالعه براى زنان شامل؛ زنانى كـهـ

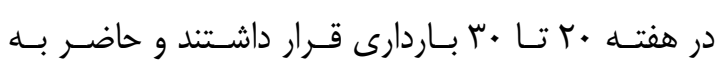

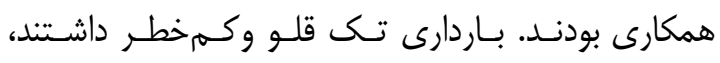

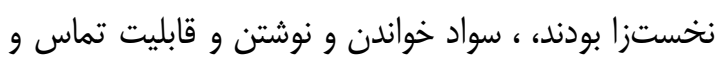

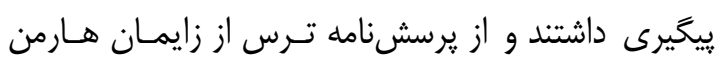

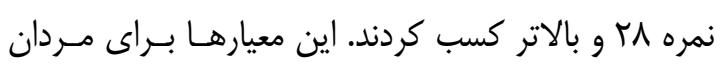

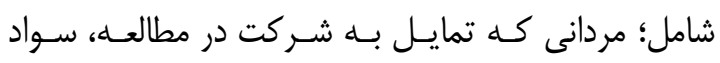

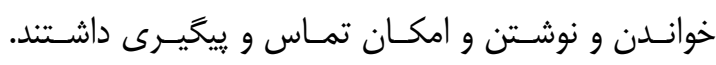

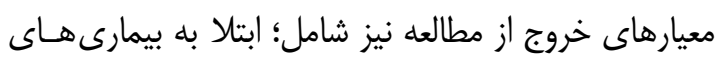

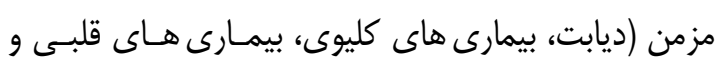

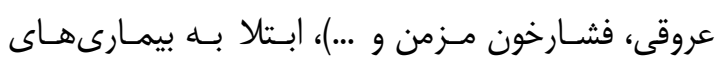

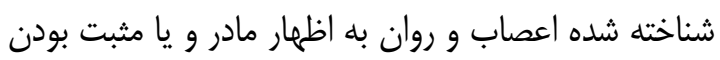

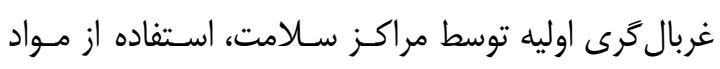

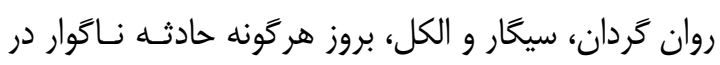

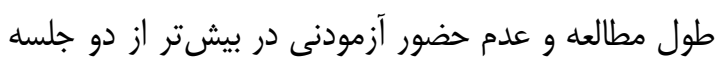
كلاس آمادگى براى زايمان بود.

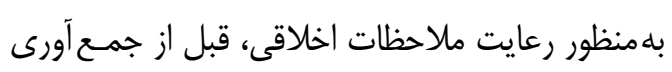

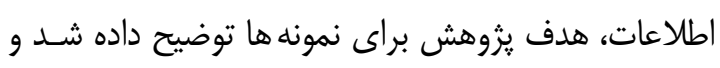

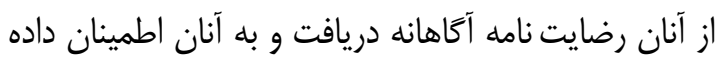
شد كه اطلاعاتشان محرمانه خواهد ماند و هر زمـان كـهـ انهان 


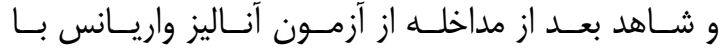

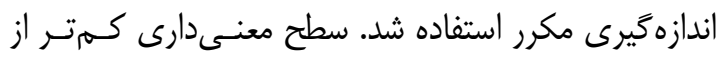

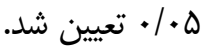

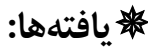

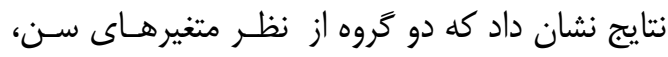

ميزان تحصيلات، شــل، تعـداد و سـن بــاردارى، ميـزان

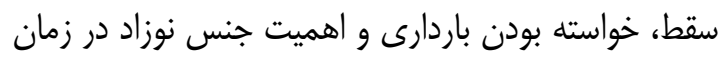

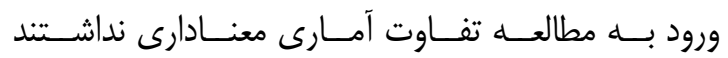

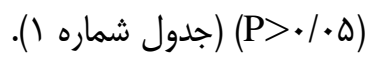

براى بررسى ميانخين نمره ترس از زايمـان در زمـان إنان

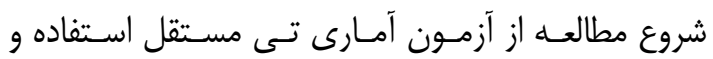

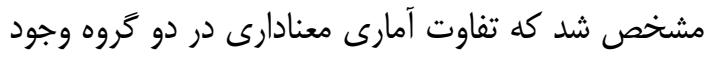

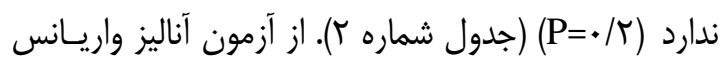

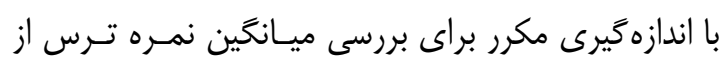

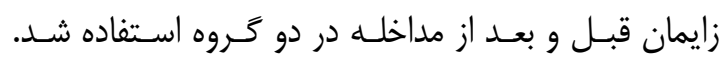

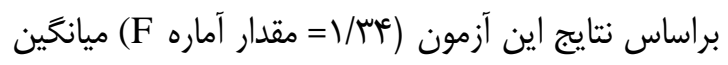

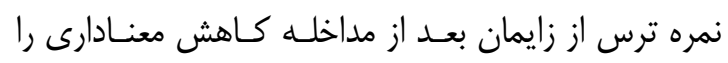

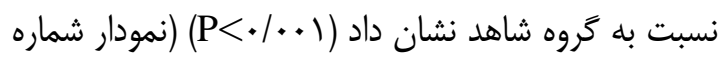

همجنين نتايج مطالعـه حاضــ نشـان داد كـه ميـزان

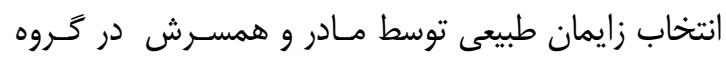

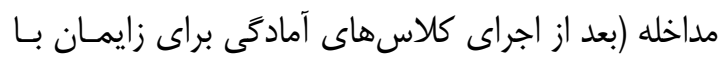

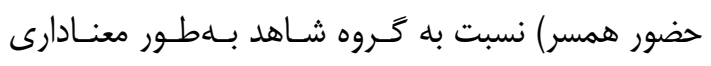

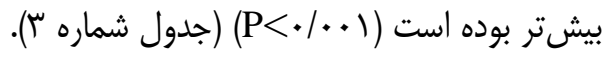

كروه شاهد نيز كلاسها مشابه كَروه مداخلـه امـا بـدون

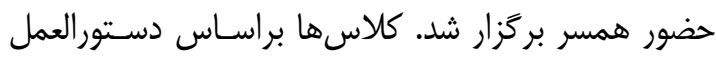

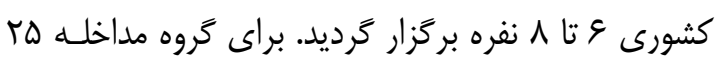

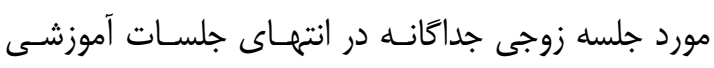
جهت ياسخ به سؤالات اختصاصى و موارد آموزشى خاص نداص

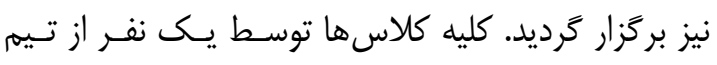
تحقيق (دانشجوى كارشناس ارشد مشاوره در مامـايى) در

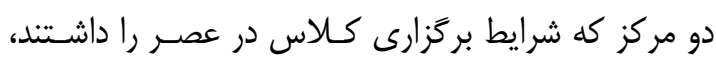

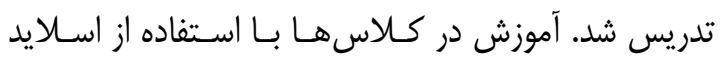

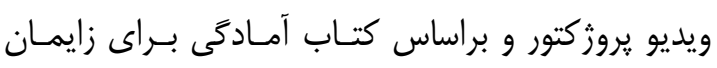

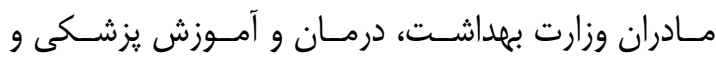
يوسترهاى معاونت بهداشتى نصب در كلاس آمادگى براى زايمان انجام گرديد.

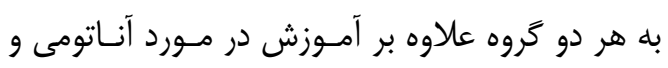

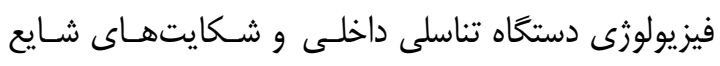

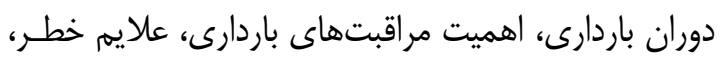

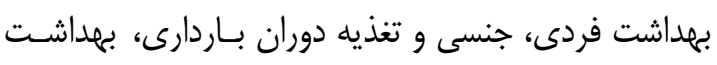

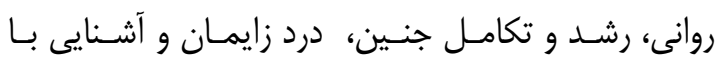

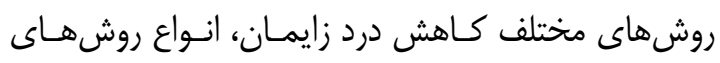

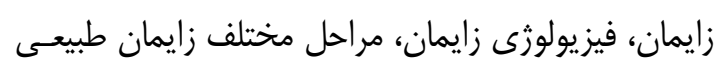
و سزارين و وضعيتهاى مختلف زايمان، اهميـت زيت زايمـان

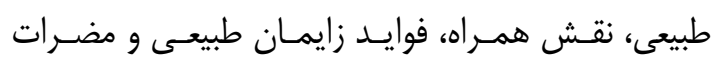

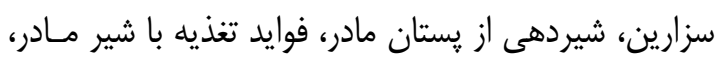

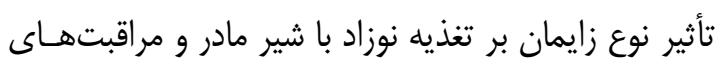

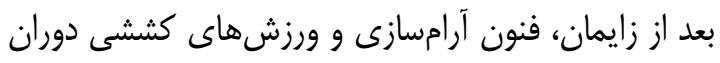
باردارى براساس دستورالعمل اداره سلامت مادران آموزش آش

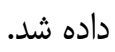

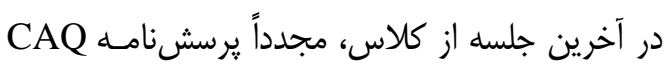

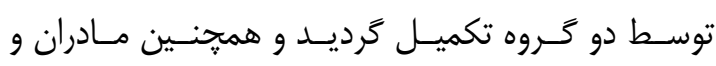

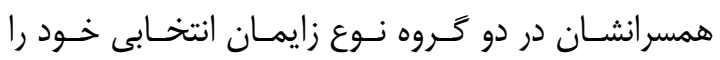

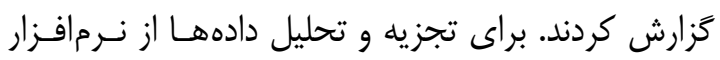

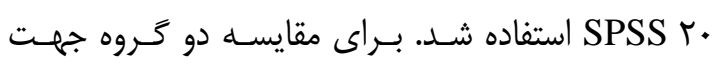

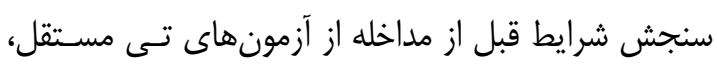
كاى دو و من ويتنى و براى مقايسه بين دو گروه مداخلـه. 
جدول (- مشخصههاى فردى و باردارى در دو تروه مداخله و شاهد (هر تروه V7نفر)

\begin{tabular}{|c|c|c|c|c|}
\hline \multirow{2}{*}{ سطح معنىدارى } & شاهد & مداخله & \multirow[t]{2}{*}{ كروهاه } & \\
\hline & \multicolumn{2}{|c|}{ (درصد) فراوانى } & & متغيرها \\
\hline$\cdot / \mathrm{V}^{*}$ & $r \Delta / Q \varepsilon \pm Y / r I$ & $r \Delta / V \Delta \pm r / \Delta r$ & \multicolumn{2}{|c|}{ سن مادر (سال) } \\
\hline $.11^{*}$ & $r / r \Delta \pm r$. & $r q / \Lambda \pm r / \cdot r$ & \multicolumn{2}{|c|}{ سن همسر (سال) } \\
\hline \multirow{3}{*}{ 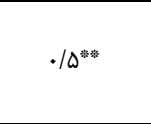 } & $1 \cdot(14 / 1)$ & $1 \cdot(1 \% / 1)$ & زيرديبلم & \multirow{3}{*}{ تحصيلات مادر } \\
\hline & TE $(r / T)$ & TI (TV/g) & دييلهم & \\
\hline & $F \cdot(\Delta T / Q)$ & $F \Delta(\Delta q / T)$ & دانشگاهى & \\
\hline \multirow{3}{*}{$\cdot / \Delta^{\text {策䊓 }}$} & $11(1 f / 4)$ & $1 f(W / F)$ & زيردييله & \multirow{3}{*}{ تحصيلات همسر } \\
\hline & $T Q(T K / Q)$ & TQ (Tr/q) & ديبلهم & \\
\hline & $r V(\& \mathcal{E N})$ & $f \cdot(f \cdot)$ & دانشگاهى & \\
\hline \multirow{4}{*}{ 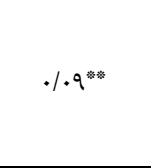 } & $\Delta V(V \Delta)$ & $\operatorname{si}(\Lambda F / T)$ & خانهدار & \multirow{4}{*}{ شغل مادر } \\
\hline & $1 \cdot(1 \% / T)$ & $r(r / q)$ & كارمند & \\
\hline & $r(r / q)$ & $\Delta(\varepsilon / \varepsilon)$ & آزاد & \\
\hline & $V(9 / T)$ & $f(\Delta / \mu)$ & ساير & \\
\hline \multirow{4}{*}{ 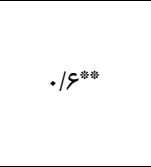 } & $\| r(\mid \Delta / \Lambda)$ & $19(4 / 1)$ & كارمند & \multirow{4}{*}{ شغل همسر } \\
\hline & $\operatorname{lr}(1 \Delta / \Lambda)$ & $10(19 / V)$ & كارگر & \\
\hline & $\operatorname{cr}(\xi) / \Lambda)$ & $r \cdot(\Delta T / \varepsilon)$ & آزاد & \\
\hline & $\Delta(\varphi / \varphi)$ & $\Delta(\varepsilon / \varphi)$ & ساير & \\
\hline \multirow{2}{*}{ 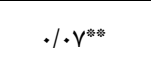 } & $V^{\mu}(q \varepsilon / 1)$ & $g \vee(\mathcal{M N} / r)$ & كافى & \multirow{2}{*}{ درآمد } \\
\hline & $r(r / q)$ & $9(11 / 1)$ & ناكافى & \\
\hline 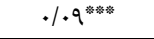 & 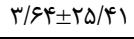 & $r \digamma / R \varepsilon \pm \Gamma / \Lambda \mu$ & \multicolumn{2}{|c|}{ سن باردارى زمان ورود به مطالعه } \\
\hline
\end{tabular}

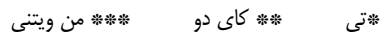

جدول r - مقايسه ميانكَين و انحراف معيار ترس از زايمان قبل از مداخله در دو تروه مداخله و شاهد

\begin{tabular}{|c|c|c|c|}
\hline سطح معنىدارى & ميانكين土|انحراف معيار & كروهاه & متغير \\
\hline \multirow{2}{*}{$\cdot / \Gamma^{*}$} & $r V / V q \pm \varepsilon / \varepsilon \Lambda$ & مداخله & \multirow{2}{*}{ ترس از زايمان } \\
\hline & $r q / 4 q \pm \Delta / v q$ & شاهد & \\
\hline
\end{tabular}

نمودار ر - مقايسه ميانكَين نمره ترس از زايمان بعد از مداخله در دو تروه مداخله و شاهد با استفاده از آزمون آناليز واريانس با اندازهيرى مكرر (Repeated Measure)

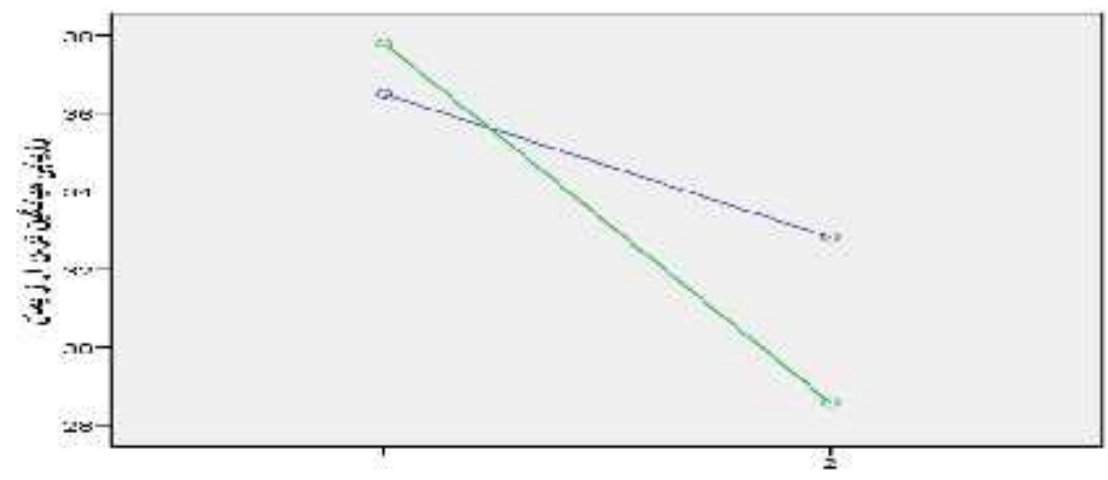


جدول سـ- مقايسه انتخاب نوع زايمان توسط مادر ان و همسر ان در دو تروه مداخله و شاهد

\begin{tabular}{|c|c|c|c|c|c|c|c|}
\hline \multirow{2}{*}{ معنى دارى } & \multirow{2}{*}{ 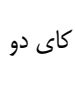 } & \multicolumn{2}{|c|}{ مداخله } & \multicolumn{2}{|c|}{ شاهد } & \multirow[t]{2}{*}{ 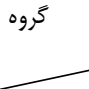 } & \multirow[b]{2}{*}{ متغير } \\
\hline & & درصد & تعداد & درصد & تعداد & & \\
\hline \multirow{2}{*}{.1 .4} & \multirow{2}{*}{$\Delta / \mu^{\prime}$} & $9 T / 1$ & v. & $\mathrm{VN} / \mathrm{q}$ & q. & طبيعى & \multirow{2}{*}{ انتخاب نوع زايمان توسط مادر } \\
\hline & & $\mathrm{V} / \mathrm{\Lambda}$ & 9 & r & 19 & سزارين & \\
\hline \multirow{2}{*}{.$/ . .1$} & \multirow{2}{*}{ שוא } & $19 / 4$ & 91 & $9 N / 4$ & $\Delta r$ & طبيعى & \multirow{2}{*}{ انتخاب نوع زايمان توسط همسر } \\
\hline & & 1.10 & $\wedge$ & $\mathrm{r} / \mathrm{d} \mathrm{VV}$ & $M^{F}$ & سزارين & \\
\hline
\end{tabular}

\section{بحث و نتيجه}

نشان دادند كه آموزش در زنان نخستزا طفى جلساتى بين

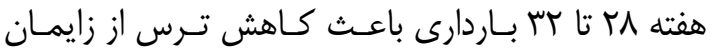
مى گردد. بنابراين ارايه اطلاعات مثبت در مورد تولد حسين

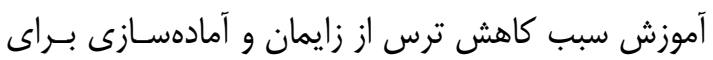

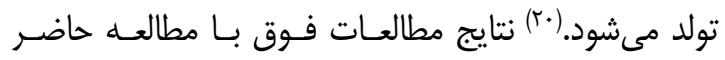
همسو مىباشد، با اين تفاوت كه مطالعات فوق آمـوزش و

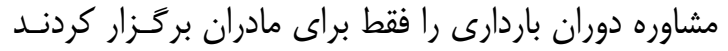

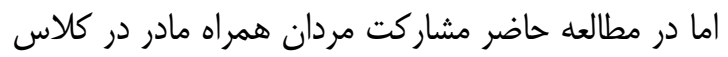

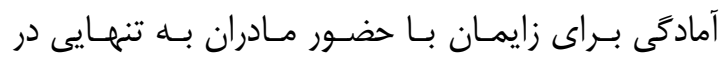
كلاسها مقايسه شده است. در مطالعات قبلى با توجه بــــ

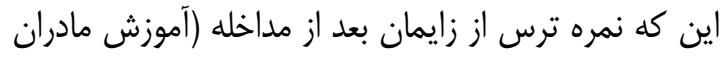

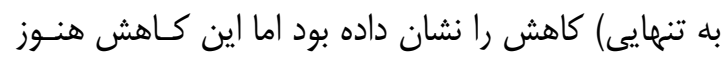

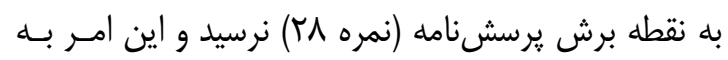
نقش و اهميت حضور و مشاركت مردان اشاره مى كند. در مطالعه حاضر مقايسه فراوانى انتخاب نوع زايمان از

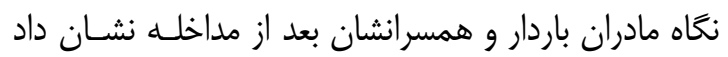
درصد بيشترى در گروه مداخله نسبت به شـاهد زايمـان

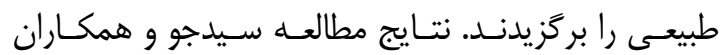

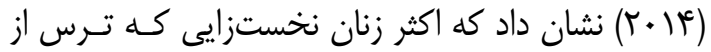

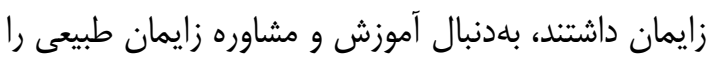

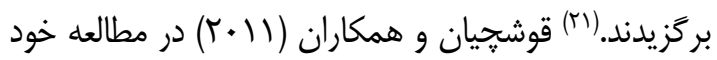

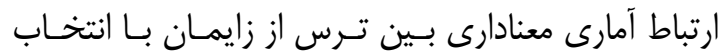

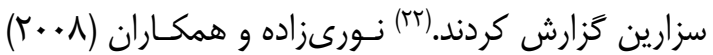
در مطالعه خود يكى از علل اصلى انتخاب سزارين راترس اترس

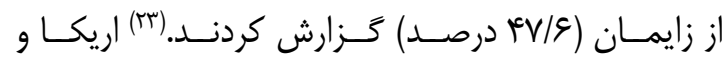
همكاران (Y. V (T) در مطالعه خود نشان دادند ترس از تولد

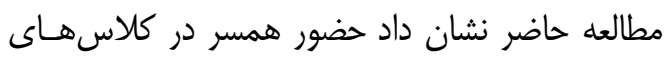

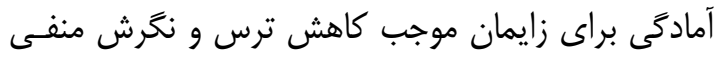
نسبت به زايمان در مادر شده است و اين كـاهش نسـبت ندات

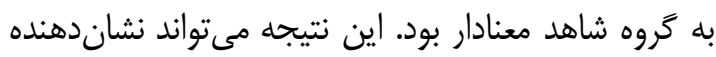

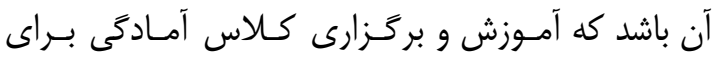
زايمان با حضور همسر در دوران باردارى مسىتوانــد نتـايج مثبتى در زمينه كاهش ترس و تغيير نخرش مادر نسبت به به

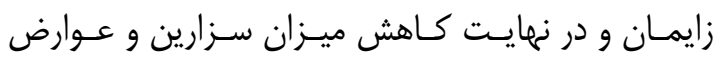
حاصل از آن را به همراه داشته باشد.

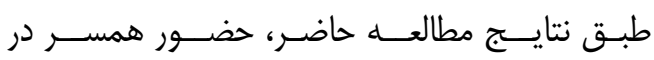
كلاسهـاى آمادگى براى زايمان ميزان ترس از زايمان رال از إز

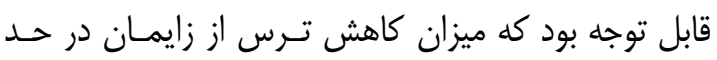

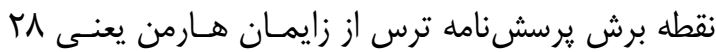

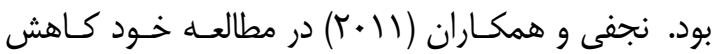

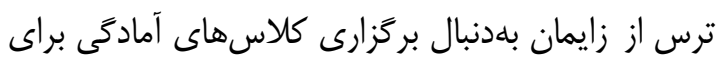

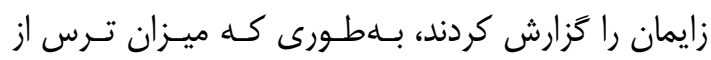

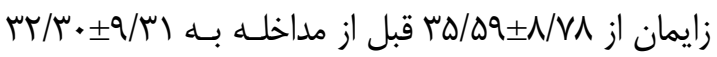

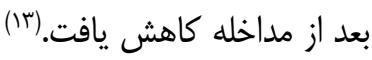

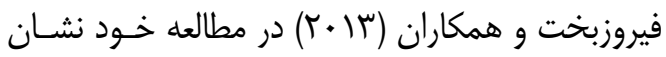

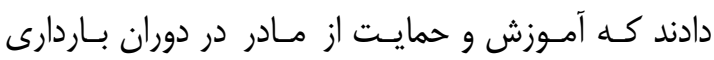

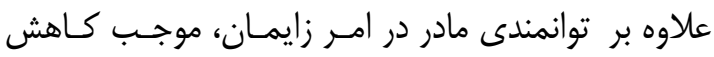
ترس و اضطراب مادر در زمان زايمان و همجنـين ايجـاد

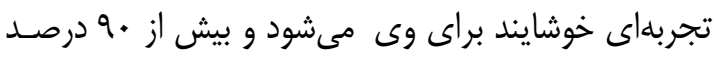

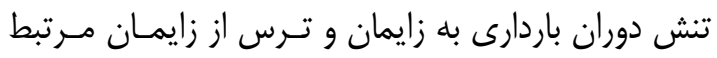

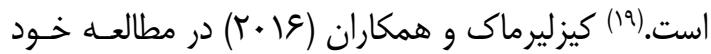


بر كيفيت اين مراقبتها و نتيجه بـاردارى، ميـزان تغذيـه

$$
\text { انحصارى با شير مادر بررسى شود. }
$$

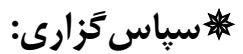

اين مقاله حاصل بخشى از پاياننامه كارشناسى ارشـــ

دانشكده يرستارى و مامايى دانشخاه علوم بزشكى قـز بـزوين

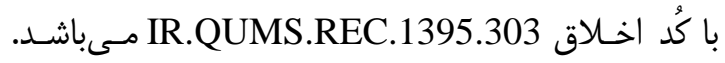

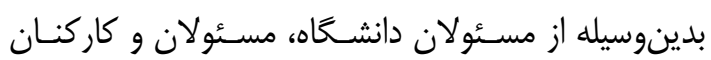

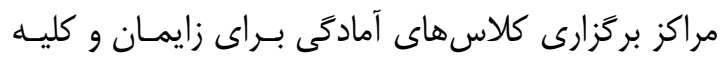

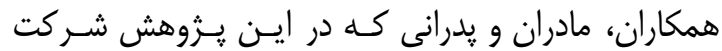

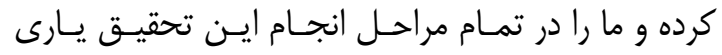

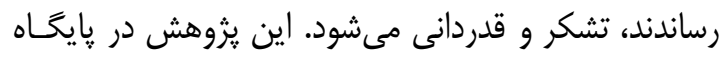
كارآزمايى بالينى به شـماره IRCT201705011113N8

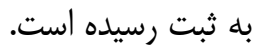

\section{مراجع}

1. Erkaya R, Karabulutlub O, Yesilcicek Calik K. Defining childbirth fear and anxiety levels in pregnant women. Procedia- Social and Behavioral Sciences 2017; 237: 1045-52. doi: 10.1016/j.sbspro.2017.02.151.

2. Marshall D, Cooper M. Myles text book for midwifes. 15th ed. Churchill livingstone; 2009. 800-820eBook ISBN: 9780702040719 3. Alipour Z, Lamyian M, Hajizadeh E, Vafaei MA. The association between antenatal anxiety and fear of childbirth in nulliparous women: a prospective study. Iran J Nurs Midwifery Res 2011; 16(2): 169-73.

4. Khorsandi M, Ghofranipour F, Heidarnia A, Faghihzadeh S, Vafaei M, Rousta F, et al. The effect of childbirth preparation classes on childbirth fear and normal delivery among primiparous women. J Arak Univ Med Sci 2008; 11(3): 29-36. [In Persian]

5. Nerum H, Halvorsen L, Sorlie T, Oian P. Maternal request for cesarean section due to fear of birth can it be changed through crisis-
كودى ممكن اسـت باعـث افـزايش اضـطراب، سـزارين

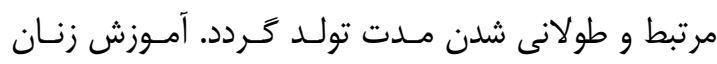

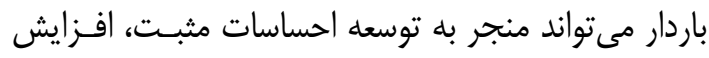

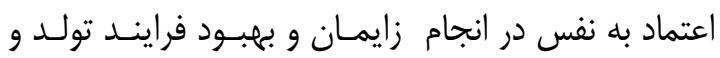

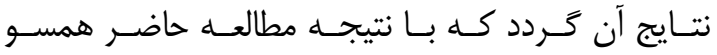

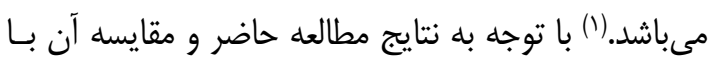

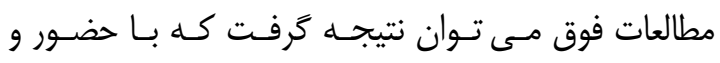

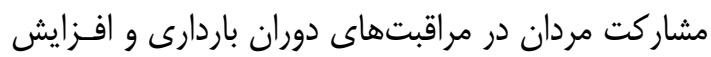

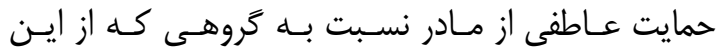

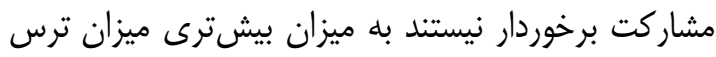

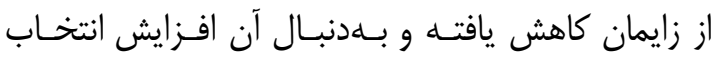
زايمان طبيعى توسط زوجين را خواهيم داشت. يزوهش حاضر نشان داد، حضور همسران و مشـاركت

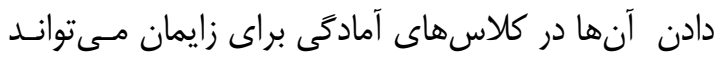

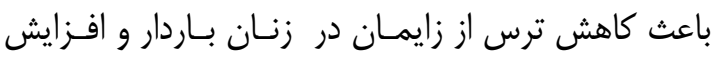

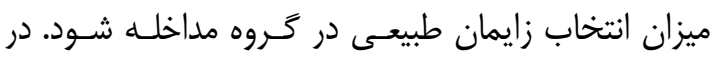
راستاى توصيه سازمان بهداشت جهانى ايـن مطالعـهـ كَام كوجكى در جهت همراهى و مشاركت مـردان در مسـايل مربوط به سلامت زنان و توجه به نقش همسر ان است. در در

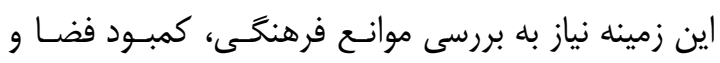

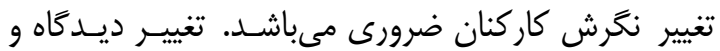

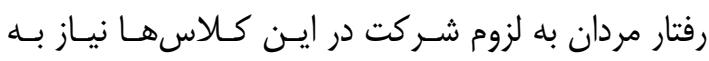

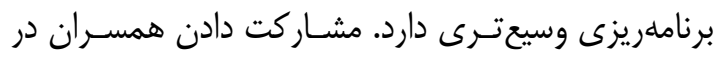

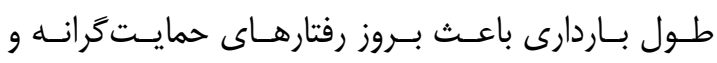
مسئولانه در مقابل مادران و كاهش ترس و اضطراب آنان

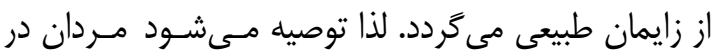
برنامههاى مختلف آموزشى مشاركت داده شوند.

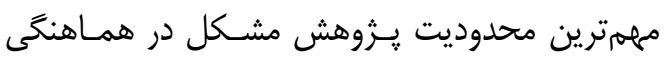
بركزارى كلاسهاى زوجى بود. بهدليل تفاوت در سـاعات

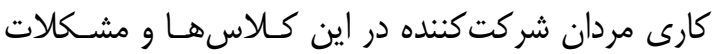

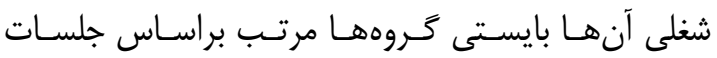

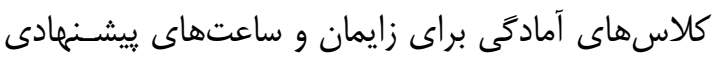
زوجين تنظيم مى كرديد. ييشـنهاد مسى شـود در مطالعـات

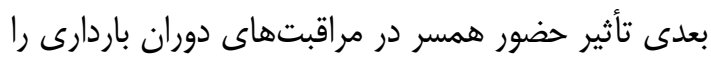


oriented counseling? Birth 2006; 33(3): 2218. doi: 10.1111/j.1523-536X.2006.00107. x. 6. Eriksson C, Westman G, Hamberg K. Content of Childbirth-Related Fear in Swedish Women and Men-Analysis of an Open-Ended Question. J Midwifery Womens Health 2006; 51(2): 112-8. doi: 10.1016/j. jmwh.2005.08.010

7. Azami-Aghdash S, Ghojazadeh $\mathrm{M}$, Dehdilani N, Mohammadi M, Asl Amin Abad R. Prevalence and Causes of Cesarean Section in Iran: Systematic Review and MetaAnalysis. Iran J Public Health 2014; 43: 54555.

8. Mortazavi F, Mirzaii K. Reason of, barriers to, and outcomes of husbands' involvement in prenatal and intrapartum care program based on midwives' experiences: a qualitative study. J Arak Univ Med Sci 2012; 15(60): 104-15. [In Persian]

9. Coutinho E, Antunes J, Duarte J, Parreira V, Chaves C, Nelas P. Benefits for the father from their involvement in the labour and birth sequence. Procedia Soc Behav Sci 2016; 217: 435-42. doi: 10.016/. sbspro2016.02.010.

10. World Health Organization. Programming for male involvement in reproductive health. Report of the meeting of WHO Regional Advisers in Reproductive Health WHO/PAHO WD, USA5-7 September 2001. Geneva: World Health Organization; 2002.

11. Dudgeon MR, Inhorn MC. Men's influences on women's reproductive health: medical anthropological perspectives. Soc Sci Med 2004;59(7): 1379-95. doi: 10.1016/j.soc scimed.2003.11.035

12. Austria G, Antonio T. Male Involvement in Maternal Health. Philippine J Health Res Develop (PJHRD) 2017; 21(2): 25-32.

13. Najafi F, Abouzari-Gazafroodi K, Jafarzadeh-Kenarsari F, Rahnama P, Gholami
Chaboki B. Relationship between attendance at childbirth preparation classes and fear of childbirth and type of delivery. Hayat 2016; 21(4): 30-40. [In Persian]

14. Kaye DK, Kakaire O, Nakimuli A, Osinde MO, Mbalinda SN, Kakande. Male involvement during pregnancy and childbirth: men's erceptions, practices and experiences during the care for women who developed childbirth complications in Mulago Hospital, Uganda. BMC Pregnancy Childbirth 2014; 14: 54. doi: 10.1186/1471-2393-14-54.

15. Alio AP, Lewis CA, Scarborough K, Harris K, Fiscella K. A community perspective on the role of fathers during pregnancy: a qualitative study. BMC Pregnancy Childbirth 2013; 13: 60. doi: 10. 1186/1471-2393-13-60.

16. Moridi A, Modarres M, Behboodi Moghadam Z, Rahimi Forooshani A. The effect of education program of the couples based on the ASNEF Model on Spousal Support and Mental Health of Pregnant Women. Glob J Health Sci 2016; 9(6): 88.

17. Dadipoor S, Alavi A, Safari Moradabadi A. A survey of the growing trend of caesarian section in Iran and the world: a review article. Iran J Obstet Gynecol Infertil 2016, 19(27): 8-17.

18. Tanglakmankhong K, Perrin NA, Lowe NK. Childbirth self-ees questionnaire: psychometric properties of Thai language versions. J Adv Nurs 2011; 67(1): 193-203. doi: 10.1111/j.1365-2648.2010.05479.x.

19. Firouzbakht M, Nikpour M, Salmalian H, Ledari FM, Khafri S. The effect of perinatal education on Iranian mothers' stress and labor pain. Glob J Health Sci 2013; 6(1): 61-8. doi: 10.5539/gjhs.v6n1p61.

20. Kızılırmak A, Başer M. The effect of education given to primigravida women on 
fear of childbirth. Appl Nurs Res 2016; 29: 19-24. doi: 10.1016/j.apnr.2015.04.002.

21. Sydsjö G, Bladh M, Lilliecreutz C, Persson A-M, Vyoni H, Josefson A. Obstetric outcomes for nulliparous women who received routine individualized treatment for severe fear of childbirth-a retrospective case control study. BMC Pregnancy Childbirth 2014; 14: 126. doi: 10.1186/1471-2393-14126.
22. Ghooshghianghoobmasjedi S, Dehghani M, Khorsandi M, Farzad V. The role of fear of pain and related psychological variables in prediction of cesarean labor. J Arak Univ Med Sci 2011; 14(3): 45-54. [In Persian]

23. Nouri Zadeh R, Kazempour R, Mohammadpour A, Bakhtari Aghdam F. Selection of mode of delivery and its related factors in pregnana women in Marand. J Urmia Nursing and Midwifery Faculty 2009; 7(1): 49-57. 